\title{
2 A comparison of multicomponent electrosorption in capacitive deionization
}

\section{and membrane capacitive deionization}

4

Armineh Hassanvand ${ }^{\mathrm{a}}$, George Q. Chen ${ }^{\mathrm{a}, \mathrm{b}}$, Paul A. Webley ${ }^{\mathrm{a}}$, Sandra E. Kentish ${ }^{\mathrm{a}, \mathrm{b}, *}$

5

${ }^{\text {a }}$ School of Chemical and Biomedical Engineering, University of Melbourne, Parkville, VIC

6 3010, Australia

7

${ }^{\mathrm{b}}$ The ARC Dairy Innovation Hub, Department of Chemical Engineering, University of

8 Melbourne, Parkville, VIC 3010, Australia

9 *Corresponding Author:

10 E-mail address: sandraek@unimelb.edu.au (S.E.Kentish).

11 Postal address: School of Chemical and Biomedical Engineering, The University of

12 Melbourne, Parkville, 3010 Victoria, Australia

13 Tel.: +61383446682. 


\section{Abstract}

15 In this study, the desalination performance of Capacitive Deionization (CDI) and Membrane 16 Capacitive Deionization (MCDI) was studied for a wide range of salt compositions. The 17 comprehensive data collection for monovalent and divalent ions used in this work enabled us 18 to understand better the competitive electrosorption of these ions both with and without ion19 exchange membranes (IEMs). As expected, MCDI showed an enhanced salt adsorption and 20 charge efficiency in comparison with CDI. However, the different electrosorption behavior of

21 the former reveals that ion transport through the IEMs is a significant rate-controlling step in the desalination process. A sharper desorption peak is observed for divalent ions in MCDI,

23 which can be attributed to a portion of these ions being temporarily stored within the IEMs, 24 thus they are the first to leave the cell upon discharge. In addition to salt concentration, we 25 monitored the $\mathrm{pH}$ of the effluent stream in CDI and MCDI and discuss the potential causes of 26 these fluctuations. The dramatic $\mathrm{pH}$ change over one adsorption and desorption cycle in CDI 27 (pH range of 3.5 to 10.5 ) can be problematic in a feed water containing components prone to scaling. The $\mathrm{pH}$ change, however, was much more limited in the case of MCDI for all salts.

Keywords: capacitive deionization; electrosorption; desalination; sulfate; nitrate; calcium. 
32 The shortage of fresh water has become a severe problem in our time owing to population and economic growth, as well as the impacts of climate change. This has made desalination of sea and brackish water stand out as an increasingly necessary answer to resolve the water crisis. Among desalination technologies, capacitive deionization (CDI) has attracted attention as an energy-efficient and promising electrochemical desalination technology, especially for low salinity brackish water (Bouhadana et al. 2010, Subramani and Jacangelo 2015). In the most common approach to CDI, the influent stream passes between two high-capacitance electrodes made of porous carbon materials to which an electrical voltage or current is applied. As a result, anions and cations are temporarily stored on the porous surface of the oppositely charged electrode and a deionized stream with lower ion concentration flows out of the cell. Ion electrosorption is based on the formation of electrical double layers (EDLs) inside the micropores $(<2 \mathrm{~nm})$ of the electrodes (Porada et al. 2013). After a period of operation, the electrodes become saturated and require regeneration. In this step, the cell voltage or current is reduced to zero and adsorbed ions are released into a wastewater stream. To summarize, a CDI cycle consists of two steps, ion adsorption and ion desorption. While CDI is only economic for relatively dilute solutions, it has low energy consumption as it removes ions from the electrolyte rather than separating water from the salty stream, such as in reverse osmosis and distillation (Asquith et al. 2015, Liu et al. 2015).

To improve performance, ion-exchange membranes (IEMs) can be placed in front of the electrodes. This approach, which is one of the most recent developments in CDI, is called Membrane Capacitive Deionization (MCDI) (Biesheuvel and van der Wal 2010). In this case, cation and anion exchange membranes placed in front of the negatively and positively charged

54 electrodes, respectively, will only allow counter-ions to move from the bulk solution toward the electrode. By blocking almost all of co-ions, the desalination process is more efficient as 
there is less co-ion repulsion. Furthermore, the use of IEMs enables us to reverse the polarity of the cell during desorption, which leads to a more complete expulsion of counter-ions from the micro and macropores of the carbon (Zhao et al. 2012a). In addition to the favorable features of CDI including low energy consumption, easy regeneration and maintenance (Wang et al. 2015), MCDI operation is more stable which makes this technique an attractive water treatment technology for industrial applications (Kim et al. 2010). Biesheuvel et al. (Biesheuvel et al. 2011), Zhao et al. (Zhao et al. 2012a) and Dykstra et al. (Dykstra et al. 2016a) have presented comprehensive ion transport models for desalination using MCDI.

Ion charge and size plays an important role, given that the CDI process is based on temporary adsorption of ions inside the EDLs of the carbon micropores. However, few studies on CDI performance have focused on salts other than $\mathrm{NaCl}$. Pioneers of this work were Gabelich et al. (Gabelich et al. 2002) who investigated the sorption capacity of carbon aerogel electrodes for various monovalent and divalent ions. They reported that monovalents are preferentially removed over divalent ions due to smaller hydrated radii. Zhao et al. (Zhao et al. 2012b) similarly observed preferential adsorption of $\mathrm{Na}^{+}$over $\mathrm{Ca}^{2+}$; however, they reported $\mathrm{Na}^{+}$ replacement with $\mathrm{Ca}^{2+}$ later during adsorption. In contrast, $\mathrm{Xu}$ et al. (Xu et al. 2008) and Mossad et al. (Mossad et al. 2013, Mossad and Zou 2012) recognized ionic charge as the factor controlling the electrosorption preference in a competitive environment. It is worth mentioning that the last three research groups studied the CDI performance with an electrolyte consisting of non-equal concentration of ions. In other words, as the ion concentration is one of the variables influencing the removal rate of that specific ion, it is questionable to attribute the preferential electrosorption sequence reported by them to ionic charge alone. A few studies have investigated the effect of ion properties on electrosorption while keeping the concentration equal for different salts. Seo et al. (Seo et al. 2010) reported selective ion removal for a mixture of cations including sodium, potassium, magnesium and calcium at different flow 
rates. They attributed the adsorption sequence to the pore size and structure of the carbon material. In another work, Huyskens et al. (Huyskens et al. 2013) measured the ion removal for various monovalent and divalent salts; however, their result was not in agreement with that of Seo et al (Seo et al. 2010). Later, Han et al. (Han et al. 2014), in a comprehensive data collection on removal of various monovalent ions in CDI using different activated carbon cloths, showed that sorption capacity and competitive ion removal can be tuned by varying the accessible surface area of carbon and its micro to meso-porosity ratio. Discrepancies between these reports indicate that more research is needed to fully understand the competitive electrosorption of different ions, especially in the presence of divalent ions. In the area of EDL modelling, (Suss 2017) extended the existing models by accounting for ion volume exclusion interactions to demonstrate selective ion removal based on ion size.

The focus in MCDI has predominantly been on the removal of different salts using novel electrodes or IEMs (Kim et al. 2016, Kim and Choi 2012). However, very few research groups have compared the removal rate of different ions in MCDI using commercially available IEMs. In 2012, Kim et al. (Kim et al. 2013) manipulated the removal of chloride and nitrate in single and mixed solutions by varying the current density in MCDI. In a recent publication, Tang et al. (Tang et al. 2017b) studied the removal of sulfate in MCDI and observed more sulfate removal in a mixture of sulfate and chloride with equal molar concentrations. As diffusion of the ions through the IEMs occurs prior to ion adsorption inside the micropores, these are crucial in controlling the diffusion. To date, little effort has been made to compare the competitive removal of different cations and anions in $\mathrm{CDI}$ to that in MCDI at milliequivalent concentrations.

Another phenomena that is mostly overlooked in this area is the $\mathrm{pH}$ fluctuation over one adsorption/desorption cycle. Only recently have He et al. (He et al. 2016) and Gao et al. (Gao et al. 2017) addressed this issue over a range of CDI operating conditions. Tang et al. (Tang et 
al. 2017a) probed into details of $\mathrm{pH}$ fluctuation in batch mode operation of CDI and MCDI by

107 monitoring the concentration of $\mathrm{H}_{2} \mathrm{O}_{2}$ and dissolved oxygen, and measuring the electrode

108 potentials. Yet, we believe this phenomenon requires more research especially for a wide range

109 of monovalent and divalent salts.

110 In this work, we aim to investigate the role of ion affinity to both the carbon electrode and the

111 ion exchange membrane. To cover a wide range of ionic properties, experiments are conducted

112 with $\mathrm{NaCl}, \mathrm{KCl}, \mathrm{CaCl}_{2}, \mathrm{NaNO}_{3}$, and $\mathrm{Na}_{2} \mathrm{SO}_{4}$ for single and mixed electrolyte solutions in both

$113 \mathrm{CDI}$ and MCDI cells. To better understand the competitive electrosoption process, experiments 114 were conducted at milliequivalent concentrations.

117 In this work, we utilized the analytical grade of all chemicals. Activated carbon (AC Norit SA

118 4, Cabot Norit Activated Carbon, USA), polyvinylidene fluoride (PVDF, Mw 530,000,

119 Sigma-Aldrich), N-N dimethylformamide (DMF, 99.8\%, Merck Millipore) and graphite sheet

120 (DSN 530, Suzhou Dasen Electronics Material Co., China) were utilized for electrode

121 fabrication. Sodium chloride $(\mathrm{NaCl}, 99.7 \%)$, potassium chloride $(\mathrm{KCl}, 99 \%)$, calcium chloride

$122\left(\mathrm{CaCl}_{2}, 99 \%\right)$, sodium nitrate $\left(\mathrm{NaNO}_{3}, 99 \%\right)$ and sodium sulfate $\left(\mathrm{Na}_{2} \mathrm{SO}_{4}, 99 \%\right)$ were used to 123 prepare electrolyte solutions. Solutions were prepared using water purified with a Millipore 124 RIOs Large with a resistance of $1 \mathrm{M} \Omega \mathrm{cm}$.

126 Preparation of carbon electrodes using AC Norit SA4 as the carbon source, PVDF as the binder

127 and DMF as the solvent is explained in detail in our previous work (Hassanvand et al. 2017). 
128 Electrodes of $10 \mathrm{~cm}$ by $20 \mathrm{~cm}$ with a narrow channel of $0.3 \mathrm{~cm}$ by $8 \mathrm{~cm}$ were fabricated using 129 graphite sheet as the current collector. The carbon content was limited to $6.5 \pm 0.5 \mathrm{mg} \mathrm{cm}^{-2}$ and 130 the apparent thickness of the electrode materials cast on the current collector was $150 \pm 15 \mu \mathrm{m}$ 131 obtained from SEM images. The prepared electrodes were then characterized using a surface 132 and pore analyzer and cyclic voltammetry. The BET surface area was calculated as $540 \pm 4 \mathrm{~m}^{2}$

$133 \mathrm{~g}^{-1}$, and pore size distribution was indicative of a microporous structure with pore diameters 134 ranging from 0.7 to $1.5 \mathrm{~nm}$. For more details see our previous work (Hassanvand et al. 2017).

135 The CDI cell consists of two parallel AC electrodes sheets with a $0.9 \mathrm{~mm}$ gap which is filled 136 by a non-conductive spacer (Low Foulant spacer 34 mil, Sterlitech). Anion and cation137 exchange membranes (Neosepta AMX, thickness of $170 \mu \mathrm{m}$, and Neosepta CMX, thickness of $138140 \mu \mathrm{m})$ are placed in front of the carbon electrodes, to configure the MCDI cell. All layers in 139 the stack are compressed into a poly(carbonate) housing. A DC power module (N6731B, 140 Agilent) in a modular power system mainframe (N6700B, Agilent) was used as the power 141 source and electrical voltage and current across the cell was recorded at a rate of 1 reading per 142 second.

143 Adsorption was conducted at a constant electrical voltage of $1.5 \mathrm{~V}$ while desorption followed 144 at zero voltage in CDI and a reversed polarity of $-1.5 \mathrm{~V}$ in MCDI. In the single-pass mode of 145 operation, the feed solution passed through the cell at a flow rate of $20 \mathrm{ml} \mathrm{min} \mathrm{m}^{-1}$ using a 146 peristaltic pump (NEMA 4X, Watson Marlow) and conductivity and pH (S470-kit, Mettler

147 Toledo) of the effluent was monitored. Conductivity data are converted to salt concentration 148 using the calibration curve corresponding to each salt. Salt adsorption $(Q)$ in $\left(\mathrm{mmol}_{\text {salt }} \mathrm{g}_{\text {carbon }}{ }^{-}\right.$ $149{ }^{1}$ ) can be calculated as below:

$$
Q=\frac{\left(\int_{0}^{t_{a d s}}\left(C_{i n}-C_{t}\right) \cdot d t\right) \cdot \dot{V}}{M_{\text {carbon }}}
$$


150 where tads is the adsorption duration, $C_{i n}$ is the inlet salt concentration, $C_{t}$ is the outlet salt

151 concentration at any time $t, \dot{V}$ is the volumetric flow rate, and $M_{\text {carbon }}$ is the total mass of 152 carbon in the electrodes.

153 Experiments were conducted in a series of single-salt and multi-salt electrolyte solutions using $154 \mathrm{NaCl}, \mathrm{KCl}, \mathrm{CaCl}_{2}, \mathrm{NaNO}_{3}, \mathrm{Na}_{2} \mathrm{SO}_{4}$. The feed concentration in single-salt and mixed solution 155 experiments was selected as $10 \mathrm{mM}$ for $1: 1$ salts and $5 \mathrm{mM}$ for $\mathrm{CaCl}_{2}$ and $\mathrm{Na}_{2} \mathrm{SO}_{4}$ to maintain 156 the ionic strength of the individual ions constant. Each experiment was repeated twice and the 157 results presented are after a number of sufficient absorption/desorption cycles to ensure consistent behavior between each cycle. Table 1 summarized the properties of the selected ions.

159 Table 1. Physical properties of the studied ions (Mossad and Zou 2012, Nightingale 1959, Robinson 160 and Stokes 1970, Sata 2004).

161 To further evaluate the cell performance, energy consumption and charge efficiency are 162 determined. Total charge $(\sigma)$ can be obtained by integrating the electrical current $\left(I_{e}\right)$ passed 163 through the cell over the adsorption time.

$$
\sigma=\int_{0}^{t_{a d s}} I_{e}(t) \cdot d t
$$

164 Then knowing the voltage applied $\left(V_{\text {Cell }}\right)$, energy consumption $\left(\mathrm{Wh} \mathrm{m}^{-3}\right)$ during an adsorption 165 step is calculated from the following equation:

$$
E=\frac{V_{\text {Cell }} \cdot \sigma}{3600\left(t_{a d s} \cdot \dot{V}\right)}
$$

166 Charge efficiency is defined as the ratio of salt removed over the amount of charge transferred

167 through the cell. As efficiency is unitless, the charge is divided by the Faraday constant to be 168 expressed as moles of electrons; and the amount of salt adsorbed is placed in terms of moles 169 into Eq. (4) as below: 


$$
\Lambda=\frac{Q \cdot M_{\text {carbon }}}{\sigma / F}
$$

170 The normalized charge efficiency takes account of the requirement for multiple charges to be

171 transferred for a multivalent salt of valence $z$ (Eq. (5))

$$
\Lambda_{n}=\frac{Q_{n} \cdot M_{\text {carbon }}}{\sigma / F}=\frac{z \cdot Q \cdot M_{\text {carbon }}}{\sigma / F}
$$

172 The concentration of individual cations $\left(\mathrm{Na}^{+}, \mathrm{K}^{+}, \mathrm{Ca}^{2+}\right)$ was analyzed using Inductively coupled plasma (ICP-OES $720 \mathrm{ES}$, Varian). The instrument detection limits is $0.03 \mu \mathrm{g} \mathrm{L}^{-1}$ for Ca, $1 \mu \mathrm{g}$

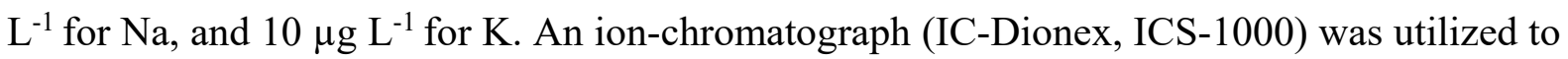
determine the concentration of $\mathrm{Cl}^{-}, \mathrm{NO}_{3}{ }^{-}$and $\mathrm{SO}_{4}{ }^{2-}$. A Dionex IONPAC AS-13 column was utilized with a retention time of $15 \mathrm{~min}$ and flow rate of $1 \mathrm{~mL} \mathrm{~min}{ }^{-1}$.

\section{Results and discussion}

\subsubsection{Feed solutions containing a single salt}

180

To probe the comparative removal of different cations, $10 \mathrm{mM}$ solutions of $\mathrm{NaCl}, \mathrm{KCl}$ or a 5 mM solution of $\mathrm{CaCl}_{2}$ was fed to the (M)CDI cell in a single pass mode. Fig. 1(a) shows the concentration variation over one cycle in CDI. It was previously reported for CDI that, at the same initial concentration, the hydrated radius governs the sorption capacity (Gabelich et al. 2002). Similarly, in this experiment, $\mathrm{KCl}$ is removed marginally faster from the electrolyte in comparison with $\mathrm{NaCl}$ in terms of mmol of salt adsorbed per gram of carbon material (Fig.

187 potassium over sodium in CDI to the higher diffusivity coefficient of the former. Suss (Suss 2017) in his recent publication on EDL modelling achieved greater separation of potassium 
over sodium by accounting for ion volume exclusion interaction. On the other hand, the difference between monovalent and divalent cations is readily distinguishable. The molar electrosorption capacity of $\mathrm{CaCl}_{2}$ is much lower than that of $\mathrm{NaCl}$ and $\mathrm{KCl}$ as shown in Fig. 2(a), $0.07 \mathrm{mmol} \mathrm{g}^{-1}$ for $\mathrm{CaCl}_{2}$ versus 0.13 and $0.15 \mathrm{mmol} \mathrm{g}^{-1}$ for $\mathrm{NaCl}$ and $\mathrm{KCl}$, respectively.

193 However, it must be noted that for each $\mathrm{Ca}^{2+}$ two electrons are consumed. The normalized 194 equivalent capacity (valence $\times$ molar adsorption capacity) of $\mathrm{CaCl}_{2}$ is competitive with that of the monovalent ions $\left(0.14 \mathrm{mmol} \mathrm{g}^{-1}\right)$. There are no significant differences in this normalized charge efficiency when equivalent concentrations of the $\mathrm{Na}^{+}, \mathrm{K}^{+}$and $\mathrm{Ca}^{2+}$ are set equal in the 197 feed.

198 However, it is noticeable that in the CDI cell, the $\mathrm{Ca}^{2+}$ adsorbs more slowly than the monovalent ions, with the lowest concentration during adsorption occurring later than for $\mathrm{K}^{+}$ and $\mathrm{Na}^{+}$; and the concentration at the end of the adsorption cycle not fully recovering. Similarly, while the desorption peak occurs at the same time for all three ions, the recovery to the feed concentration is slightly extended for calcium. These effects probably reflect the slower diffusion rate of calcium, given its larger size.

204 Close inspection of Fig. 1(a) reveals a minor increase at the beginning of each adsorption step, with this increase greatest for $\mathrm{KCl}$. As regeneration occurs at zero voltage, some undesired coion adsorption happens during this desorption step. Consequently, when the cell voltage is reapplied during the subsequent adsorption step, an abrupt repulsion of these co-ions occurs, which then results in a repulsion peak (Zhao et al. 2013). The extent of co-ion adsorption is greatest for $\mathrm{KCl}$ consistent with the normalized capacity and its small hydrated radius.

210 In the next series of experiments, ion-exchange membranes were placed in front of the 211 electrodes to provide an MCDI arrangement (Fig. 1(b)). In these experiments, while the 212 adsorption duration was kept similar to CDI, a shorter desorption time was required as 
213 described in Section 3.2 above. When using IEMs, there are fewer differences in concentrations

214 between ions and the charge efficiency is significantly higher (Fig. 2(b)) as has been noted by

215 other authors (Zhao et al. 2012a, Zhao et al. 2013). The repulsion peak at the beginning of the

216 adsorption step is also no longer present, confirming that the peak observed in CDI arises from

217 co-ion repulsion and does not arise from immobile chemical charges or inverted CDI, as

218 described by Biesheuvel et al. (Biesheuvel et al. 2015) and Gao et al. (Gao et al. 2016).

Fig. 1. Changes in effluent salt concentration obtained experimentally in (a) CDI, and (b) MCDI cell in the treatment of $\mathrm{NaCl}, \mathrm{KCl}$ and $\mathrm{CaCl}_{2}$ individually as single salt experiments.

Fig. 2. Experimental salt adsorption and charge efficiency of (a) CDI, and (b) MCDI cell in the treatment of $\mathrm{NaCl}, \mathrm{KCl}$ and $\mathrm{CaCl}_{2}$ individually as single salt experiments.

219 In the MCDI cell the salt adsorption of $\mathrm{NaCl}$ is slightly higher than that of $\mathrm{KCl}$, although they both have similar charge efficiency, $94.8 \%$ and $96.2 \%$, respectively (Fig. 2(b)). It is apparent that, for these monovalent ions, the effect of hydrated radii is no longer relevant, suggesting that the IEMs themselves are now governing the mass transfer. Similarly, with equivalent ionic strength of cations, $\mathrm{CaCl}_{2}$ is behaving very similar to the monovalent electrolytes in contrast to what was observed in CDI. While the salt adsorption capacity is identical, there is evidence of marginally smaller charge efficiency, which may arise from the slow diffusion of $\mathrm{Ca}^{2+}$ through the IEM and into the porous carbon electrode.

Molar salt adsorption was determined to be $0.12 \mathrm{mmol} \mathrm{g}^{-1}$ for $\mathrm{CaCl}_{2}$ flowing in the MCDI cell which has almost doubled in comparison to the CDI case. Indeed, the normalized charge efficiency of MCDI is uniformly high. This enhancement is owing to co-ion blockage and regeneration at reversed voltage when using MCDI. When the polarity is reversed, the counterions, i.e. the ions having opposite charge to the electrode during adsorption, not only leave the micropores of the carbon electrodes, but the macropores also become depleted. Hence, in the 
233 following adsorption step, there is more driving force for the ions of opposite charge to diffuse

234 through the macropores and adsorb into the electrical double-layers inside the micropores.

235 Conversely, in CDI, when the voltage drops to zero, the adsorbed ions are repulsed; however,

236 their concentration in the macropores of the carbon only drops to that of the bulk stream.

\subsubsection{Feed solutions containing a salt mixture}

Deionization experiments were next conducted using a single solution containing a mixture of $10 \mathrm{mM}$ of $\mathrm{NaCl}, \mathrm{KCl}$ and $5 \mathrm{mM} \mathrm{CaCl}_{2}$ in a single-pass mode. As a salt mixture is used, the concentrations of each salt must be determined by ion analysis, rather than simple conductivity.

241 Hence, after observing five consecutive stable adsorption-desorption cycles as evidenced by conductivity monitoring, samples were taken at the exit of the cell for individual ion analysis at a number of time points during the ensuing cycle. Fig. 3 depicts the result of competitive

244 removal of the three different cations in CDI and MCDI, respectively, while Table 2 provides

245 the equivalent adsorption capacity, based on an integration of the areas over the respective absorption and desorption periods.

247 As shown in Fig. 3(a), for CDI, in the early stages of electrosorption, the potassium and sodium ions recover from co-ion repulsion faster and adsorb onto the cathode faster than calcium. However, after five minutes of adsorption, the effluent concentration of monovalent ions is

250 higher than that of calcium, which now dominates the adsorption process. Similarly, potassium

251 is the first to desorb from the cathode. These observations are similar to that reported previously in CDI (Seo et al. 2010, Zhao et al. 2012b).

Fig. 3. Competitive electrosorption of $\mathrm{Na}^{+}, \mathrm{K}^{+}$and $\mathrm{Ca}^{2+}$ based on ion analysis of the effluent stream in (a) CDI, (b) MCDI in the mixed salt experiment. Symbols represent ion analyses, while lines are a guide for the eye. 
Table 2. Equivalent adsorption of each ion oven one cycle of CDI and MCDI in the case of mixed cations obtained from Fig. 3.

The preferential ion sorption can be explained through the interplay of two phenomena: (i) diffusion kinetics, (ii) adsorption equilibria. Due to the smaller hydrated radii of monovalent ions, they diffuse more rapidly into the micropores, resulting in initially greater uptake of $\mathrm{KCl}$ $>\mathrm{NaCl}>\mathrm{CaCl}_{2}$. However, adsorption equilibria, either determined experimentally (Hou and Huang 2013) or predicted by modified-Donnan EDL-theory (Zhao et al. 2012b), indicates that $\mathrm{Ca}^{2+}$ is more strongly adsorbed and will ultimately replace these ions in a mixed ion solution. Zhao et al. (Zhao et al. 2012b) demonstrated these effects to show how the operating process can be manipulated to achieve an effluent rich in either monovalent ions (over short time frames) or divalent ions (over long timeframes). Seo at al. (Seo et al. 2010) also showed that sodium removal efficiency is lower than calcium and magnesium owing to substitution of the adsorbed $\mathrm{Na}^{+}$by divalent ions over time. Hou and Huang (Hou and Huang 2013) find that in an equimolar mixture of salts, $\mathrm{Ca}^{2+}$ is adsorbed most strongly, followed by $\mathrm{K}^{+}$and then $\mathrm{Na}^{+}$. The activated carbon used by Hou and Huang showed a wider pore size distribution to that used in this work (Hassanvand et al. 2017), which might facilitate the diffusion of larger hydrated ions such as calcium. Our own results show $\mathrm{K}^{+}$with the strongest normalized sorption capacity, but this is closely followed by $\mathrm{Ca}^{2+}$ (Table 2).Ion analysis shows a different trend for the MCDI experiments. As noted in the single salt experiments, it is apparent that there is much

272 less significant discrepancy among the effluent concentration of each cation during the 273 adsorption step when using IEMs (Fig. 3(b)). Similar to CDI, $\mathrm{Ca}^{2+}$ adsorption dominates after an initial period where $\mathrm{K}^{+}$is more dominant. However, the differences in ion concentration is more noticeable during the desorption step. It is clear that $\mathrm{Ca}^{2+}$ leaves the MCDI cell faster relative to monovalent ions. This rapid release is somewhat unexpected given the large size and hence slow diffusion rate of the $\mathrm{Ca}^{2+}$ ion. We believe that this effect arises from the large 
capacity for $\mathrm{Ca}^{2+}$ uptake within the cation exchange membrane itself. It is well known that due

to the strong electrostatic force between divalent cations and the fixed charged groups within an IEM, that divalent counterions will be dominant within this phase in mixed cation systems. This is the basis of Donnan exclusion theory (Mulder 1996, Strathmann 2004) and has been observed by a number of workers including (Joshi and Kwak 1981) Ayala-Bribiesca et al.

283 (Ayala-Bribiesca et al. 2006) and Shee et al. (Shee et al. 2008). As a result, when the polarity is reversed, divalents are expelled quickly. In contrast, monovalents require more time to appear at the cell exit as they need to leave the micro and macro pores of the carbon, and then diffuse through the IEMs. Potassium's higher adsorption and desorption rate in comparison to sodium can be attributed to its smaller hydrated radii and higher diffusivity coefficient which helps it to electromigrate faster in comparison to $\mathrm{Na}^{+}$.

\subsection{Comparative Electrosorption capacity of different anions}

\subsubsection{Feed solutions containing a single salt}

291

Fig. 4(a) shows how the effluent concentration varies over one cycle out of five consecutive stable cycles when running single-salt experiments in CDI where the anion was varied. The total salt adsorption of $\mathrm{NaCl}$ and $\mathrm{NaNO}_{3}$ are identical within experimental error (Fig. 7(a)), although other workers have found that $\mathrm{NO}_{3}{ }^{-}$has greater sorption capacity than $\mathrm{Cl}^{-}(\mathrm{Li}$ et al. 2016). The differences in the shape of the sorption and desorption curves between these two salts probably reflect the much greater co-ion adsorption observed for $\mathrm{NO}_{3}{ }^{-}$, as indicated by the large peak at the beginning of the desorption cycle, when these adsorbed ions are repulsed by the application of a charge. It is known that $\mathrm{NO}_{3}{ }^{-}$is a relatively hydrophobic anion, as indicated by a low ratio of hydrated to ionic radius (Hydration ratio, Table 1) (Li et al. 2016), and this results in significant adsorption to the carbon when there is no charge applied. This substantial co-ion adsorption and desorption results in low charge efficiency (Fig. 7(a)) and is also the reason that the net sorption capacity is not greater than that for $\mathrm{NaCl}$. The normalized salt 
303 adsorption for $\mathrm{Na}_{2} \mathrm{SO}_{4}$ is low, relative to both $\mathrm{NaCl}$ and $\mathrm{NaNO}_{3}$ which may relate to slow

304 diffusion of the $\mathrm{SO}_{4}$ anion due to its larger hydrated radius - this is reflected in a slightly later

305 adsorption minimum concentration and desorption maximum concentration. The charge

306 efficiency is comparable to $\mathrm{NaNO}_{3}$, although there is no evidence of co-ion repulsion effects

307 in this case. This again may be because the slow diffusion rate results in a broader and flatter

308 co-ion repulsion peak that is not evident in the experimental data.

309 As with the cation experiments, the performance becomes more uniform when IEMs are

310 installed for the MCDI experiments (Fig. 4(b)) with significantly higher adsorption capacity

311 and charge efficiency in comparison to that of CDI. The peaks at the beginning of the

312 adsorption cycle are also again absent. This is because co-ion adsorption now cannot occur and

313 all charge is consumed in adsorbing the anions onto the anode. The normalized charge

314 efficiency for $\mathrm{NaCl}$ and $\mathrm{NaNO}_{3}$ is identical and close to one which is representative of an

315 energy efficient technique. Similar to the data for $\mathrm{CaCl}_{2}$ in Fig. 2(b), the charge efficiency for

$316 \mathrm{Na}_{2} \mathrm{SO}_{4}$ is slightly lower, which can be attributed to a smaller diffusivity coefficient of the

317 divalent ions through the IEMs and into the carbon.

318 Fig. 4. Changes in effluent salt concentration in (a) CDI, and (b) MCDI cell in the treatment of NaCl,

Fig. 5. Experimental salt adsorption and charge efficiency of (a) CDI, and (b) MCDI cell in the treatment of $\mathrm{NaCl}, \mathrm{NaNO}_{3}$ and $\mathrm{Na}_{2} \mathrm{SO}_{4}$ individually as single salt experiments.

\subsubsection{Feed solutions containing a salt mixture}

323 Ion analysis results of the effluent stream in a mixed salt solution of $\mathrm{NaCl}, \mathrm{NaNO}_{3}$ and $\mathrm{Na}_{2} \mathrm{SO}_{4}$

324 are shown in Fig. 6 from which the equivalent adsorption has been obtained and presented in

325 Table 3. During the adsorption step in mixed salt CDI, $\mathrm{SO}_{4}{ }^{2-}$ and $\mathrm{Cl}^{-}$are adsorbed at a faster rate in the early electrosorption period. Similar to the behavior of the multi cation experiment, 
the concentration of the first two adsorbed ions then recovers quickly to be replaced by the

$328 \mathrm{NO}_{3}^{-}$ion. As discussed above, the strong hydrophobicity of $\mathrm{NO}_{3}^{-}$means that a significant concentration is adsorbed onto the cathode during the preceding desorption step and so the

330 initial 2-3 minutes of the adsorption cycle is dominated by repulsion of these co-ions. Once

331 these ions have been recovered, the stronger sorption capacity of $\mathrm{NO}_{3}{ }^{-}$allows it to replace the

$332 \mathrm{Cl}^{-}$and $\mathrm{SO}_{4}^{2-}$ ions. Chen et al. (Chen et al. 2015) investigated the competitive electrosorption of mixed $\mathrm{Cl}^{-}$and $\mathrm{NO}_{3}{ }^{-}$and mixed $\mathrm{Cl}^{-}$and $\mathrm{SO}_{4}{ }^{2-}$ solutions and reported a similar ion substitution phenomenon for $\mathrm{NO}_{3}{ }^{-}$. They compared this behavior to ion exchange processes in which $\mathrm{NO}_{3}{ }^{-}$ is similarly selectively adsorbed relative to $\mathrm{Cl}^{-}$. In another work, Tang et al. (Tang et al. 2015) attributed the higher ion removal rate of nitrate to a stronger non-electrostatic attraction between carbon and this ion.

338 As shown in Fig. 6(b), similar behavior to that of cation mixed salt desalination (Fig. 3(b)) was observed for $\mathrm{MCDI}$. $\mathrm{Cl}^{-}, \mathrm{NO}_{3}{ }^{-}$and $\mathrm{SO}_{4}{ }^{2-}$ were removed from the salty stream at similar rates during adsorption, as a result, the salt adsorptions of all anions are quite similar. Operating MCDI under constant current, Tang et al. (Tang et al. 2017b) reported that the sorption ratio of

342 sulfate to chloride is a function of electrical current applied. Therefore the trend we observed

343 here might be slightly different at lower or higher cell voltages. Nonetheless, the fact that equimolar concentrations of sulfate and chloride was used by these authors (instead of milliequivalent concentrations) might explain the higher adsorption of sulfate in their study in comparison to ours.

347 The effect of ion properties is more noticeable when it comes to desorbing the ions from carbon

348 electrode. There is a sharper peak of sulfate desorption in the first two minutes of desorption.

349 As discussed for calcium above, we believe that this is due to the greater sorption of this divalent anion within the anion exchange membrane in a mixed ion solution. The hydrated radii 
351 of $\mathrm{Cl}^{-}$and $\mathrm{NO}_{3}{ }^{-}$are similar (see Table 1) and therefore, they are desorbed at comparable rates.

352 However, as shown in Table 3, the equivalent adsorption capacity for $\mathrm{NO}_{3}{ }^{-}$is highest, reflecting

353 its greater affinity for the carbon electrodes (lower hydration ratio).

354 From Fig. 3(b) and Fig. 6(b), it is apparent that diffusion through the membrane matrix can be

355 the rate controlling step which synchronizes the transport of the different cations and anions.

356 Most importantly, the membranes act as a storage reservoir for divalent ions, which means that

357 desorption of these ions is more rapid. This reinforces the hypothesis that during desorption,

358 ionic charge is the governing factor in MCDI, followed by hydrated radii. The more the ionic

359 charge and the smaller the hydrated radii, the faster an individual ion is desorbed. This is an

360 important finding from an application point of view as it shows that the use of ion exchange

361 membranes can significantly alter the selective electrosorption mechanisms of CDI. Careful

362 control of the desorption cycle time could provide a solution concentrated in calcium sulfate.

363 This salt is a well-known fouling agent and hence its removal could facilitate a downstream

364 reverse osmosis or evaporation operation.

365 As discussed in different sections of this study, comparing CDI experimental performance of

366 two different works seems quite complicated as there any many critical variables involved,

367 including the carbon properties (specific surface area, pore size distribution, surface groups,

368 and specific capacitance), cell configuration (electrode thickness, distance between the

369 electrodes, and spacer type), and operational parameters (feed concentration, flow rate, and

370 applied voltage). This issue further highlights the importance of developing a comprehensive

371 dynamic transport model in this area which can reflect the effect of such properties.

372 Verification of desalination rate of different salts in CDI and MCDI in a single-pass mode

373 enables us to predict the performance of these energy efficient techniques in a wide range of

374 operational condition and in treating multi-component feed. 
Fig. 6. Competitive electrosorption of $\mathrm{Cl}^{-}, \mathrm{NO}_{3}{ }^{-}$and $\mathrm{SO}_{4}{ }^{2-}$ by ion analysis of the effluent stream in (a) CDI, (b) MCDI in the mixed salt experiment. Symbols represent ion analyses, while lines are a guide for the eye.

375

376

377

378

379

380

381

382

383

384

385

386

387

Table 3. Equivalent adsorption of each ion oven one cycle of CDI and MCDI in the case of mixed anions obtained from Fig. 6.

To test the stack capacity after the completion of all experiments, $\mathrm{NaCl}$ removal was compared with the initial performance. As the effluent salt concentration was identical to this initial performance, it can be claimed that the capacity of (M)CDI cell remained constant and thus that $(\mathrm{M}) \mathrm{CDI}$ is a stable desalination method.

\section{3 pH fluctuation}

The $\mathrm{pH}$ fluctuation that occurs during adsorption and desorption of various salts during CDI and MCDI has not been studied comprehensively. We believe that monitoring the $\mathrm{pH}$ change over one cycle of adsorption and desorption is helpful to probe this issue in more detail. It should be noted that the data presented here is for a pair of carbon electrodes that had been used for at least 20 cycles. The $\mathrm{pH}$ of solutions that have been exposed to a fresh electrode fluctuates more significantly, as the surface of the fresh carbon contains functional groups that are initially reactive with water.

Fig. 7(a,b) demonstrate the fluctuation of effluent $\mathrm{pH}$ in CDI and MCDI for single-salt electrolytes passing through the cell in a single pass mode. While all the desalination experiments start with a feed solution of $\mathrm{pH}$ of $6.2 \pm 0.3$, the initial effluent $\mathrm{pH}$ is influenced by the previous treatment cycles. During adsorption of salt solution in the CDI configuration, the $\mathrm{pH}$ first increases and then decreases (Fig. 7(a)). The pH fluctuation reveals that Faradaic reactions (oxidation-reduction) occurs in tandem with ion electrosorption (non-faradaic effect) 
395 (He et al. 2016). This dramatic fluctuation in $\mathrm{pH}$ could lead to salt precipitation and subsequent 396 fouling of the electrodes in industrial applications, which is undesirable. Lee et al. (Lee et al. 397 2010) observed a similar $\mathrm{pH}$ trend at cell voltages above $1.0 \mathrm{~V}$. They attributed two phenomena 398 to this $\mathrm{pH}$ change: (i) reduction of dissolved oxygen at the cathode, see Eq. (6); and (ii) 399 Oxidation of anions such as $\mathrm{Cl}^{-}$at the anode which is then followed by disproportionation of $400 \mathrm{Cl}_{2}$ (Lee et al. 2010, Zhao et al. 2014). The oxygen reduction reaction may occur through a 401 four-electron (Eq. (6)) or two-electron (Eq. (7)) pathway where the latter is followed by 402 reduction of peroxide as shown in Eq. (8) (Kinoshita 1988, Song and Zhang 2008).

$$
\begin{array}{ll}
\mathrm{O}_{2}+2 \mathrm{H}_{2} \mathrm{O}+4 e^{-} \rightarrow 4 \mathrm{OH}^{-} & E^{0}=0.401 \mathrm{~V} \\
\mathrm{O}_{2}+\mathrm{H}_{2} \mathrm{O}+2 e^{-} \rightarrow \mathrm{HO}_{2}^{-}+\mathrm{OH}^{-} & E^{0}=-0.065 \mathrm{~V} \\
\mathrm{HO}_{2}^{-}+\mathrm{H}_{2} \mathrm{O}+2 e^{-} \rightarrow 3 \mathrm{OH}^{-} & E^{0}=0.867 \mathrm{~V} \\
2 \mathrm{Cl}^{-} \rightarrow \mathrm{Cl}_{2}(\mathrm{aq})+2 e^{-} & E^{0}=1.360 \mathrm{~V} \\
\mathrm{Cl}_{2}(\mathrm{aq})+\mathrm{H}_{2} \mathrm{O} \rightarrow \mathrm{HCl}+\mathrm{HOCl} &
\end{array}
$$

403 Therefore oxygen reduction in the early stages of the adsorption cycle results in a $\mathrm{pH}$ increase 404 through hydroxyl ion production. At ambient pressure and temperature, the maximum oxygen 405 solubility in a solution of $10 \mathrm{mM}$ salt is $8.2 \pm 0.1 \mathrm{mg} \mathrm{L}^{-1}$ which can result in a $\mathrm{pH}$ of around 40611 corresponding to Eq. (6) or a combination of Eqs. (7) and (8). For a closed system, as might 407 be used in an industrial application, this value is expected to be lower. It is worth noting that 408 while Tang et al. (Tang et al. 2017a) monitored oxygen reduction reactions in acidic solutions 409 by $\mathrm{H}_{2} \mathrm{O}_{2}$ formation, oxygen reduction will proceed via Eq. (6) or (7) in neutral or alkaline 410 solutions(Song and Zhang 2008).

411 However, it is apparent that $\mathrm{Cl}^{-}$oxidation (Eqs. 9 and 10) is not a valid justification for the 412 subsequent drop in $\mathrm{pH}$, as this sharp drop can also be observed for other anions, $\mathrm{NaNO}_{3}$ and 
$413 \mathrm{Na}_{2} \mathrm{SO}_{4}$. He et al. (He et al. 2016) measured $\mathrm{HOCl}$ concentration and also argued that $\mathrm{Cl}^{-}$

414 oxidation was not the cause. That research group suggested that, at $1.5 \mathrm{~V}$, water splitting (Eq.

415 (11)) and carbon oxidation (Eq. (12)) most likely contribute to the $\mathrm{pH}$ decrease after reaching 416 an early peak. They argued that the redox potential would be lower at high $\mathrm{pH}$ values which 417 makes these reactions feasible (He et al. 2016).

$$
\begin{array}{ll}
\frac{1}{2} \mathrm{H}_{2} \mathrm{O} \rightarrow \frac{1}{4} \mathrm{O}_{2}+\mathrm{H}^{+}+e^{-} & E^{0}=1.23 \mathrm{~V} \\
\frac{1}{4} \mathrm{C}+\frac{1}{2} \mathrm{H}_{2} \mathrm{O} \rightarrow \frac{1}{4} \mathrm{CO}_{2}+\mathrm{H}^{+}+e^{-} & E^{0}=0.7-0.9 \mathrm{~V}
\end{array}
$$

418 Nonetheless, as Eq. (12) occurs, carbon is consumed which leads to electrode mass loss (Porada 419 et al. 2013). Considering the stability of the (M)CDI device noted above, the likelihood of 420 significant carbon oxidation is quite low. If carbon material at the anode was significantly 421 involved in electrochemical reactions, the desalination performance would diminish with time.

Fig. 7. Effluent pH values in (a) CDI, and (b) MCDI during one adsorption desorption cycle of single salts experiments.

422 It is noteworthy that while the $\mathrm{pH}$ change during salt adsorption in CDI appears large, with a 423 peak of 10.5 and a minimum of 3.5 , the change in $\mathrm{H}^{+}$concentration is limited to only $0.3 \mathrm{mM}$. 424 This is negligible in comparison with the changes in salt concentration reported in this work. 425 As a result, the changes in the $\mathrm{H}^{+}$concentration do not affect the salt concentration 426 measurements significantly. It is also worth mentioning that the large $\mathrm{pH}$ swing is also related 427 to the relatively high voltage $(1.5 \mathrm{~V})$ used in these experiments. In processes sensitive to such $428 \mathrm{pH}$ fluctuations, we suggest operating at lower voltage despite the fact the salt removal would 429 decrease.

430 On the other hand, as represented in Fig. 7(b), the range of $\mathrm{pH}$ change in MCDI is smaller than 431 that of CDI, especially the initial increase. There are some possible explanations for this. 
432 Firstly, placing the CEM in front of the cathode reduces the access of dissolved oxygen to the 433 carbon surface. This argument was also used in the recent publication by Tang et al. (Tang et 434 al. 2017a). Secondly, for the oxygen that does reach the cathode, the $\mathrm{OH}^{-}$produced (see oxygen 435 reduction reactions) cannot easily penetrate through the cation exchange membrane to reach 436 the bulk solution. As the initial $\mathrm{pH}$ jump does not occur; therefore, the redox potentials of 437 reactions (11) and (12) are not met. Finally, not only is the occurrence of these last two 438 equations reduced, but the transport of the $\mathrm{H}^{+}$ions produced into the bulk stream is hindered 439 by the anion-exchange membrane. We also assume that any hydroxyl and hydronium ions so 440 trapped behind each ion-exchange membrane can enhance the counter-ion attraction. 441 Marginally different $\mathrm{pH}$ patterns for $\mathrm{Na}_{2} \mathrm{SO}_{4}$ and $\mathrm{CaCl}_{2}$ might reflect greater water splitting, as 442 reflected in the slightly lower charge efficiency noted for these systems, but this would require 443 further investigation.

444 A better understanding of the $\mathrm{pH}$ fluctuation would assist in the development of mathematical 445 models to account for the contribution of hydronium and hydroxyl ions. Recently, Dykstra et 446 al. (Dykstra et al. 2017) incorporated one pathway for oxygen reduction and carbon oxidation 447 into an ion transport model of MCDI to calculate the $\mathrm{pH}$ changes. However, given the much 448 greater $\mathrm{pH}$ fluctuation in the case of CDI, all Faradaic reactions must be added to the relevant 449 ion transport models to calculate the portion of voltage being dissipated within these side 450 reactions.

\section{Conclusion}

452 In this work, activated carbon electrodes were prepared and then were utilized in a CDI and 453 (M)CDI setup. Single salt electrolyte solutions of $\mathrm{NaCl}, \mathrm{KCl}, \mathrm{CaCl}_{2}, \mathrm{NaNO}_{3}, \mathrm{Na}_{2} \mathrm{SO}_{4} \mathrm{Were}$ tested as were solutions containing mixtures of three cations and three anions. The results show that the charge efficiency of $\mathrm{NO}_{3}{ }^{-}$and $\mathrm{SO}_{4}{ }^{2-}$ is lower in $\mathrm{CDI}$ than for other anions which can 
456 be attributed to strong co-ion adsorption and to slow rates of diffusion. Salt adsorption and

457 charge efficiency boosted significantly when IEMs were introduced in front of the electrodes.

458 Importantly, once IEMs were in place, there was a change in the order of desorption, with

459 divalent cations and anions giving a stronger desorption peak. We believe that this relates to

460 the IEMs acting as storage reservoirs for these ions reducing the path length of diffusion before

461 release. The limited $\mathrm{pH}$ change in MCDI adds to the advantage of this technique over CDI

462 since a vigorous $\mathrm{pH}$ increase and decrease is not favorable to fresh water production.

\section{Acknowledgements}

464 Armineh Hassanvand acknowledges The University of Melbourne for the IPRS (International

465 Postgraduate Research Scholarship) and APA (Australian Postgraduate Awards) scholarships,

466 which are funded by the Australian Government. George Chen and Sandra Kentish

467 acknowledge research funding from the Australian Research Council Industrial

468 Transformation Research Program (ITRP) scheme (Project Number IH120100005). The ARC

469 Dairy Innovation Hub is a collaboration between The University of Melbourne, The University

470 of Queensland and Dairy Innovation Australia Ltd. George Chen acknowledges support from

471 an Early Career Researcher (ECR) Grant awarded by the Melbourne School of Engineering,

472 The University of Melbourne. We are grateful to Professor Benny Freeman (The University of

473 Texas at Austin) who provided expertise in ion transport through IEMs. We would also like to

474 acknowledge the Particulate Fluid Processing Centre at the University of Melbourne) for 475 infrastructure support.

476 
478 Asquith, B.M., Meier-Haack, J. and Ladewig, B.P. (2015) Poly(arylene ether sulfone) 479 copolymers as binders for capacitive deionization activated carbon electrodes. Chem. Eng. Res. 480 Des. 104, 81-91.

481 Ayala-Bribiesca, E., Araya-Farias, M., Pourcelly, G. and Bazinet, L. (2006) Effect of 482 concentrate solution $\mathrm{pH}$ and mineral composition of a whey protein diluate solution on 483 membrane fouling formation during conventional electrodialysis. Journal of Membrane 484 Science 280(1), 790-801.

485 Biesheuvel, P.M., Hamelers, H.V.M. and Suss, M.E. (2015) Theory of Water Desalination by 486 Porous Electrodes with Immobile Chemical Charge. Colloids Interface Sci. Commun. 9, 1-5.

487 Biesheuvel, P.M. and van der Wal, A. (2010) Membrane capacitive deionization. J. Membr. 488 Sci. 346(2), 256-262.

489 Biesheuvel, P.M., Zhao, R., Porada, S. and van der Wal, A. (2011) Theory of membrane 490 capacitive deionization including the effect of the electrode pore space. Journal of Colloid and 491 Interface Science 360(1), 239-248.

492 Bouhadana, Y., Avraham, E., Soffer, A. and Aurbach, D. (2010) Several basic and practical 493 aspects related to electrochemical deionization of water. AIChE J. 56(3), 779-789.

494 Chen, Z., Zhang, H., Wu, C., Wang, Y. and Li, W. (2015) A study of electrosorption selectivity 495 of anions by activated carbon electrodes in capacitive deionization. Desalination 369, 46-50.

496 Dykstra, J., Zhao, R., Biesheuvel, P. and Van der Wal, A. (2016a) Resistance identification 497 and rational process design in Capacitive Deionization. Water Research 88, 358-370. 
Dykstra, J.E., Dijkstra, J., van der Wal, A., Hamelers, H.V.M. and Porada, S. (2016b) On-line method to study dynamics of ion adsorption from mixtures of salts in capacitive deionization. Desalination 390, 47-52.

Dykstra, J.E., Keesman, K.J., Biesheuvel, P.M. and van der Wal, A. (2017) Theory of pH 502 changes in water desalination by capacitive deionization. Water Research 119, 178-186.

503 Gabelich, C.J., Tran, T.D. and Mel Suffet, I.H. (2002) Electrosorption of Inorganic Salts from 504 Aqueous Solution Using Carbon Aerogels. Environ. Sci. Technol. 36(13), 3010-3019.

505 Gao, X., Omosebi, A., Holubowitch, N., Landon, J. and Liu, K. (2017) Capacitive Deionization 506 Using Alternating Polarization: Effect of Surface Charge on Salt Removal. Electrochimica 507 Acta 233, 249-255.

508 Gao, X., Porada, S., Omosebi, A., Liu, K.L., Biesheuvel, P.M. and Landon, J. (2016) 509 Complementary surface charge for enhanced capacitive deionization. Water Res. 92, 275-282.

510 Han, L., Karthikeyan, K.G., Anderson, M.A. and Gregory, K.B. (2014) Exploring the impact 511 of pore size distribution on the performance of carbon electrodes for capacitive deionization. 512 Journal of Colloid and Interface Science 430(0), 93-99.

513 Hassanvand, A., Chen, G.Q., Webley, P.A. and Kentish, S.E. (2017) Improvement of MCDI 514 operation and design through experiment and modelling: Regeneration with brine and optimum 515 residence time. Desalination 417, 36-51.

516 He, D., Wong, C.E., Tang, W., Kovalsky, P. and Waite, T.D. (2016) Faradaic Reactions in

517 Water Desalination by Batch-Mode Capacitive Deionization. Environmental Science \& 518 Technology Letters.

519 Hou, C.-H. and Huang, C.-Y. (2013) A comparative study of electrosorption selectivity of ions 520 by activated carbon electrodes in capacitive deionization. Desalination 314(0), 124-129. 
521 Huyskens, C., Helsen, J. and de Haan, A.B. (2013) Capacitive deionization for water treatment:

522 Screening of key performance parameters and comparison of performance for different ions.

523 Desalination 328(0), 8-16.

524 Joshi, Y.M. and Kwak, J.C.T. (1981) The binding of divalent metal ions to polyelectrolytes in 525 mixed counterion systems. Biophysical Chemistry 13(1), 65-75.

526 Kim, J.S., Jeon, Y.S. and Rhim, J.W. (2016) Application of poly(vinyl alcohol) and polysulfone

527 based ionic exchange polymers to membrane capacitive deionization for the removal of mono528 and divalent salts. Separation and Purification Technology 157, 45-52.

529 Kim, Y.-J. and Choi, J.-H. (2012) Selective removal of nitrate ion using a novel composite 530 carbon electrode in capacitive deionization. Water Research 46(18), 6033-6039.

531 Kim, Y.-J., Hur, J., Bae, W. and Choi, J.-H. (2010) Desalination of brackish water containing 532 oil compound by capacitive deionization process. Desalination 253(1-3), 119-123.

533 Kim, Y.-J., Kim, J.-H. and Choi, J.-H. (2013) Selective removal of nitrate ions by controlling 534 the applied current in membrane capacitive deionization (MCDI). Journal of Membrane 535 Science 429, 52-57.

536 Kinoshita, K. (1988) Carbon: electrochemical and physicochemical properties.

537 Lee, J.-H., Bae, W.-S. and Choi, J.-H. (2010) Electrode reactions and adsorption/desorption 538 performance related to the applied potential in a capacitive deionization process. Desalination $539258(1), 159-163$.

540 Li, Y., Zhang, C., Jiang, Y., Wang, T.-J. and Wang, H. (2016) Effects of the hydration ratio on 541 the electrosorption selectivity of ions during capacitive deionization. Desalination 399, 171542177. 
543 Liu, Y., Nie, C., Liu, X., Xu, X., Sun, Z. and Pan, L. (2015) Review on carbon-based composite

544 materials for capacitive deionization. RSC Adv. 5(20), 15205-15225.

545 Mossad, M., Zhang, W. and Zou, L. (2013) Using capacitive deionization for inland brackish 546 groundwater desalination in a remote location. Desalination 308, 154-160.

547 Mossad, M. and Zou, L. (2012) A study of the capacitive deionisation performance under

548 various operational conditions. Journal of hazardous materials 213-214(0), 491-497.

549 Mulder, M. (1996) Basic Principles of Membrane Technology, Dordrecht; Boston: Kluwer 550 Academic.

551 Nightingale, E.R., Jr. (1959) Phenomenological theory of ion solvation. Effective radii of 552 hydrated ions. J. Phys. Chem. 63, 1381-1387.

553 Porada, S., Zhao, R., van der Wal, A., Presser, V. and Biesheuvel, P.M. (2013) Review on the 554 science and technology of water desalination by capacitive deionization. Progress in Materials 555 Science 58(8), 1388-1442.

556 Robinson, R.A. and Stokes, R.H. (1970) Electrolyte solutions, [electronic resource] the 557 measurement and interpretation of conductance, chemical potential, and diffusion in solutions 558 of simple electrolytes, London, Butterworths [1965, reprinted 1970]2d ed., rev.

559 Sata, T. (2004) Ion exchange membranes: preparation, characterization, modification and 560 application, Royal Society of Chemistry.

561 Seo, S.-J., Jeon, H., Lee, J.K., Kim, G.-Y., Park, D., Nojima, H., Lee, J. and Moon, S.-H. (2010)

562 Investigation on removal of hardness ions by capacitive deionization (CDI) for water softening applications. Water Research 44(7), 2267-2275. 
564 Shee, F.L.T., Angers, P. and Bazinet, L. (2008) Microscopic approach for the identification of 565 cationic membrane fouling during cheddar cheese whey electroacidification. Journal of Colloid 566 and Interface Science 322(2), 551-557.

567 Song, C. and Zhang, J. (2008) Electrocatalytic oxygen reduction reaction. PEM Fuel Cell 568 Electrocatalysts and Catalyst Layers: Fundamentals and Applications 1, 92.

569 Strathmann, H. (2004), Ion-exchange membrane separation processes, Amsterdam; Boston: $570 \quad$ Elsevier.

571 Subramani, A. and Jacangelo, J.G. (2015) Emerging desalination technologies for water 572 treatment: A critical review. Water Res. 75, 164-187.

573 Suss, M.E. (2017) Size-based ion selectivity of micropore electric double layers in capacitive 574 deionization electrodes. arXiv preprint arXiv:1704.04156.

575 Tang, W., He, D., Zhang, C., Kovalsky, P. and Waite, T.D. (2017a) Comparison of Faradaic 576 reactions in capacitive deionization (CDI) and membrane capacitive deionization (MCDI) 577 water treatment processes. Water Research 120, 229-237.

578 Tang, W., He, D., Zhang, C. and Waite, T.D. (2017b) Optimization of sulfate removal from brackish water by membrane capacitive deionization (MCDI). Water Research 121, 302-310.

580 Tang, W., Kovalsky, P., He, D. and Waite, T.D. (2015) Fluoride and nitrate removal from 581 brackish groundwaters by batch-mode capacitive deionization. Water Res. 84, 342-349.

582 Wang, C., Song, H., Zhang, Q., Wang, B. and Li, A. (2015) Parameter optimization based on 583 capacitive deionization for highly efficient desalination of domestic wastewater biotreated 584 effluent and the fouled electrode regeneration. Desalination 365, 407-415. 
585 Xu, P., Drewes, J.E., Heil, D. and Wang, G. (2008) Treatment of brackish produced water using

586 carbon aerogel-based capacitive deionization technology. Water Research 42(10-11), 2605-

5872617.

588 Zhao, R., Biesheuvel, P.M. and van der Wal, A. (2012a) Energy consumption and constant 589 current operation in membrane capacitive deionization. Energy Environ. Sci. 5(11), 95205909527.

591 Zhao, R., van Soestbergen, M., Rijnaarts, H.H.M., van der Wal, A., Bazant, M.Z. and 592 Biesheuvel, P.M. (2012b) Time-dependent ion selectivity in capacitive charging of porous 593 electrodes. J. Colloid Interface Sci. 384(1), 38-44.

594 Zhao, Y., Hu, X.-m., Jiang, B.-h. and Li, L. (2014) Optimization of the operational parameters 595 for desalination with response surface methodology during a capacitive deionization process. 596 Desalination 336, 64-71.

597 Zhao, Y., Wang, Y., Wang, R., Wu, Y., Xu, S. and Wang, J. (2013) Performance comparison 598 and energy consumption analysis of capacitive deionization and membrane capacitive 599 deionization processes. Desalination 324, 127-133.

600

601 
603 Fig. 1. Changes in effluent salt concentration obtained experimentally in (a) CDI, and (b)

$604 \mathrm{MCDI}$ cell in the treatment of $\mathrm{NaCl}, \mathrm{KCl}$ and $\mathrm{CaCl}_{2}$ individually as single salt experiments.

605 Fig.2. Experimental salt adsorption and charge efficiency of (a) CDI, and (b) MCDI cell in the 606 treatment of $\mathrm{NaCl}, \mathrm{KCl}$ and $\mathrm{CaCl}_{2}$ individually as single salt experiments.

607 Fig.3. Competitive electrosorption of $\mathrm{Na}^{+}, \mathrm{K}^{+}$and $\mathrm{Ca}^{2+}$ based on ion analysis of the effluent 608 stream in (a) CDI, (b) MCDI in the mixed salt experiment. Symbols represent ion analyses, 609 while lines are a guide for the eye.

610 Fig. 4. Changes in effluent salt concentration in (a) CDI, and (b) MCDI cell in the treatment of $611 \mathrm{NaCl}, \mathrm{NaNO}_{3}$ and $\mathrm{Na}_{2} \mathrm{SO}_{4}$ individually as single salt experiments.

612 Fig. 5. Experimental salt adsorption and charge efficiency of (a) CDI, and (b) MCDI cell in the 613 treatment of $\mathrm{NaCl}, \mathrm{NaNO}_{3}$ and $\mathrm{Na}_{2} \mathrm{SO}_{4}$ individually as single salt experiments.

614 Fig.6. Competitive electrosorption of $\mathrm{Cl}^{-}, \mathrm{NO}_{3}{ }^{-}$and $\mathrm{SO}_{4}{ }^{2-}$ by ion analysis of the effluent stream 615 in (a) CDI, (b) MCDI in the mixed salt experiment. Symbols represent ion analyses, while lines 616 are a guide for the eye.

617 Fig. 7. Effluent $\mathrm{pH}$ values in (a) CDI, and (b) MCDI during one adsorption desorption cycle of 618 single salts experiments. 
620 Table Captions:

621 Table 1. Physical properties of the studied ions (Mossad and Zou 2012, Nightingale 1959, 622 Robinson and Stokes 1970, Sata 2004).

623 Table 2. Equivalent adsorption of each ion oven one cycle of CDI and MCDI in the case of 624 mixed cations obtained from Fig. 3.

625 Table 3. Equivalent adsorption of each ion oven one cycle of CDI and MCDI in the case of 626 mixed anions obtained from Fig. 6.

627 


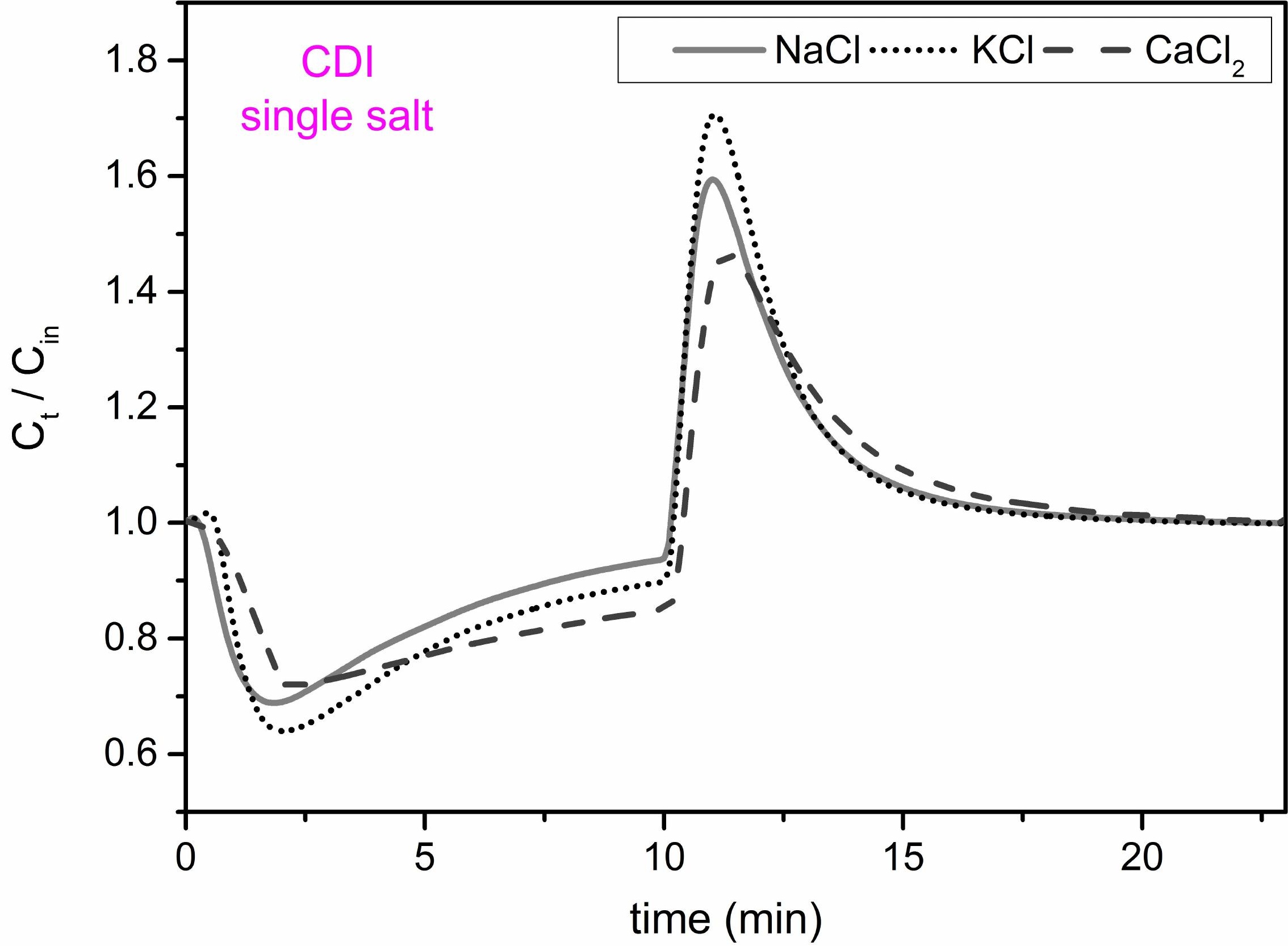




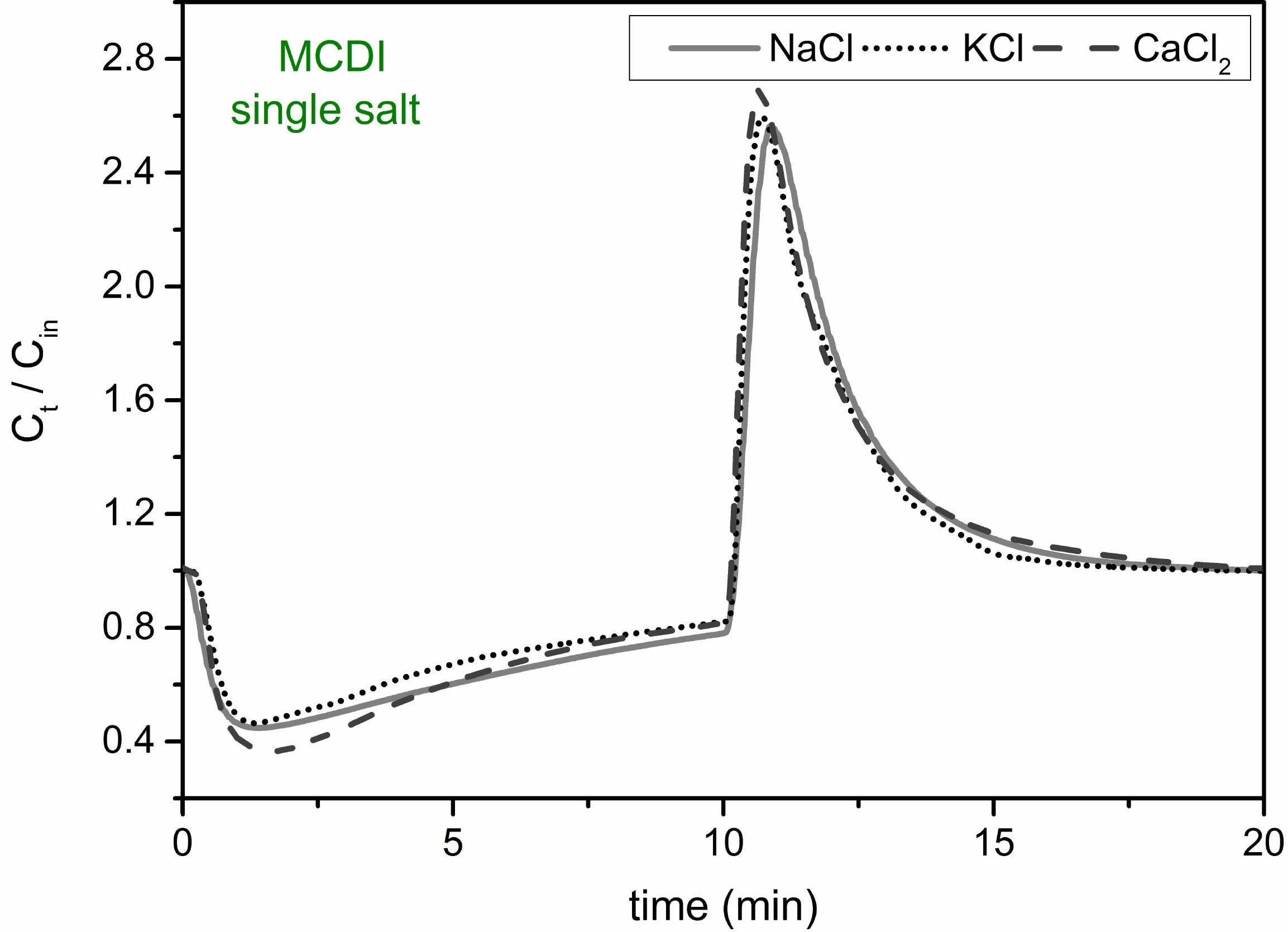




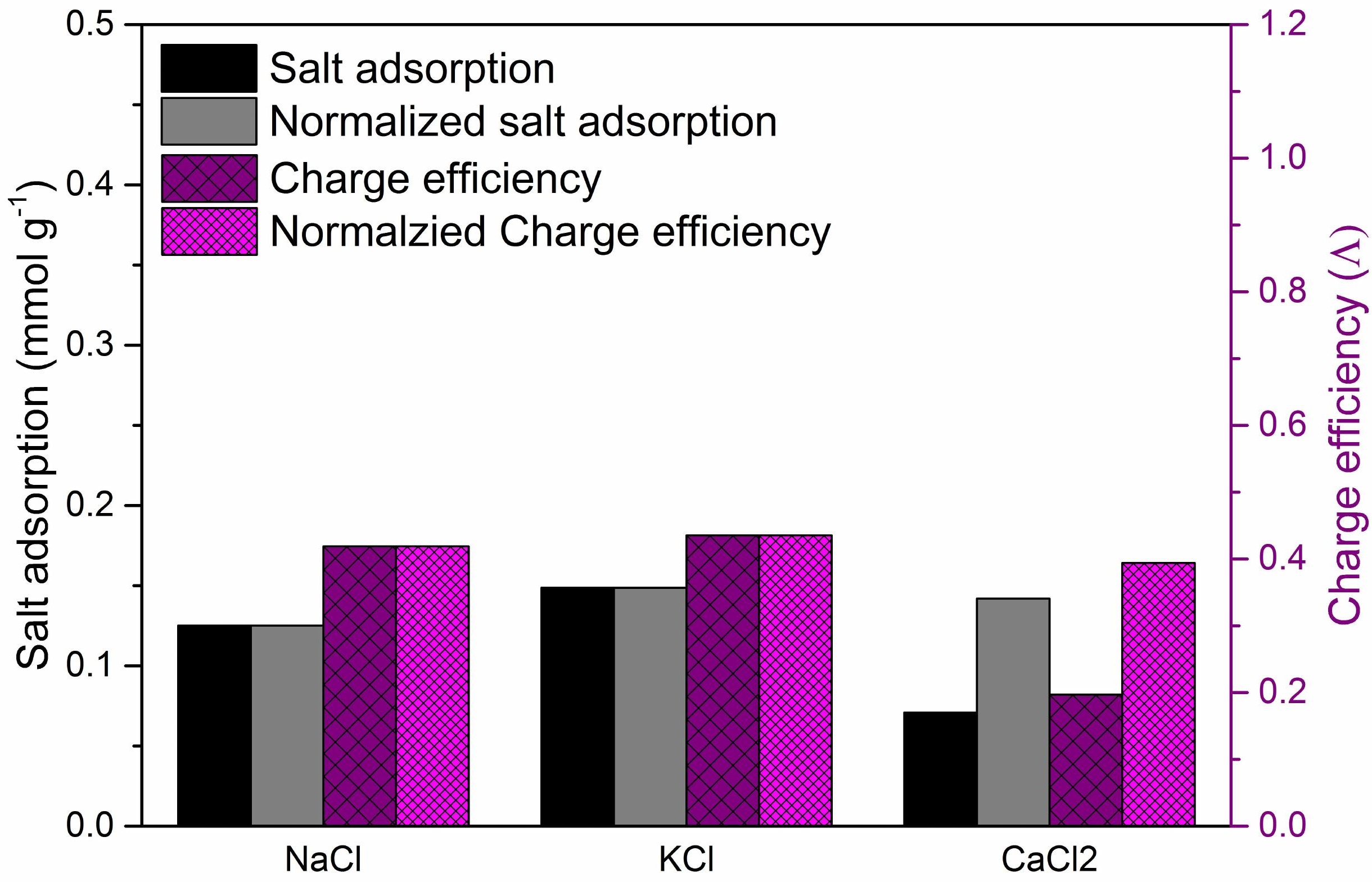




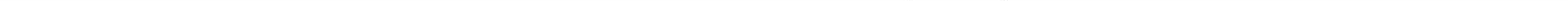




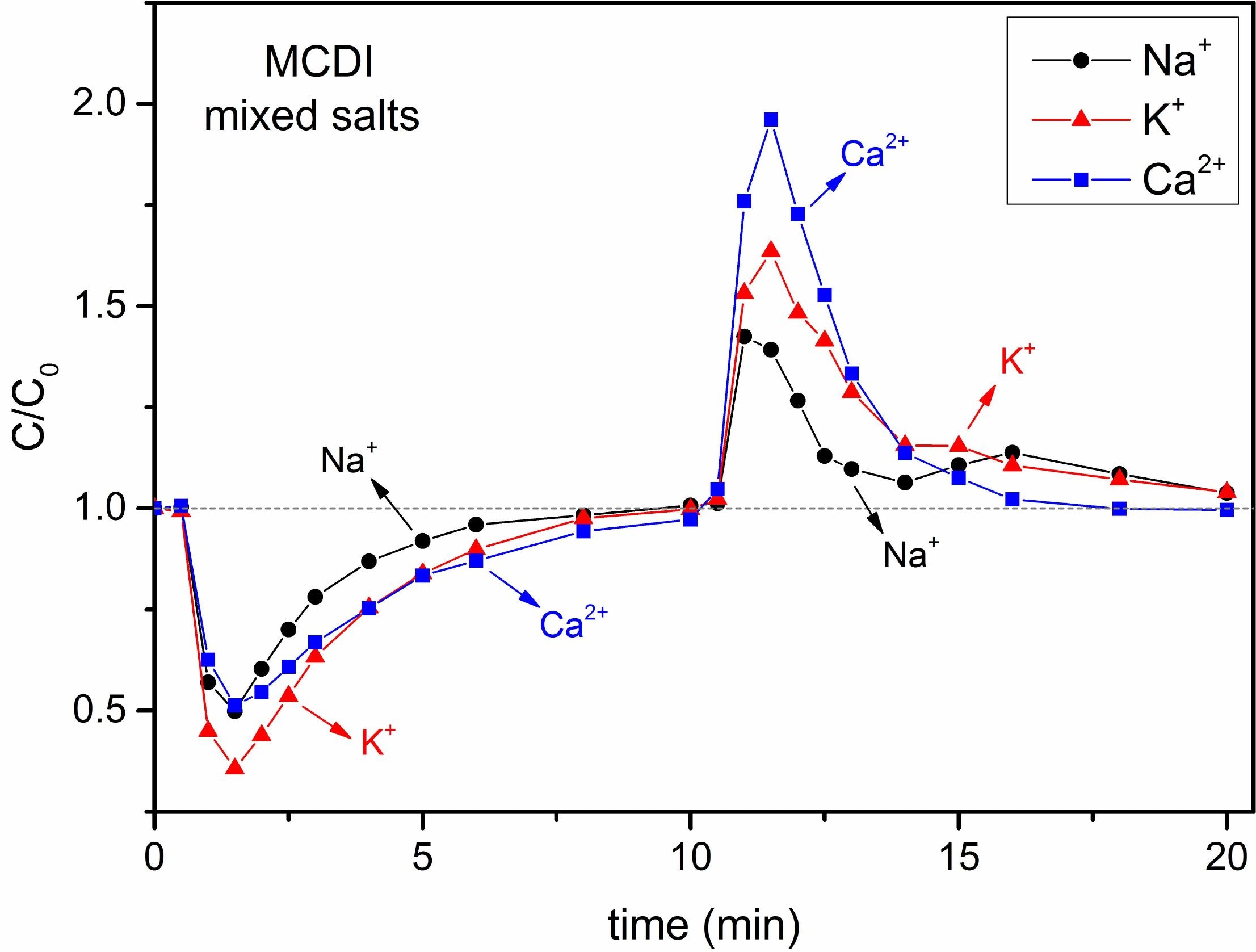




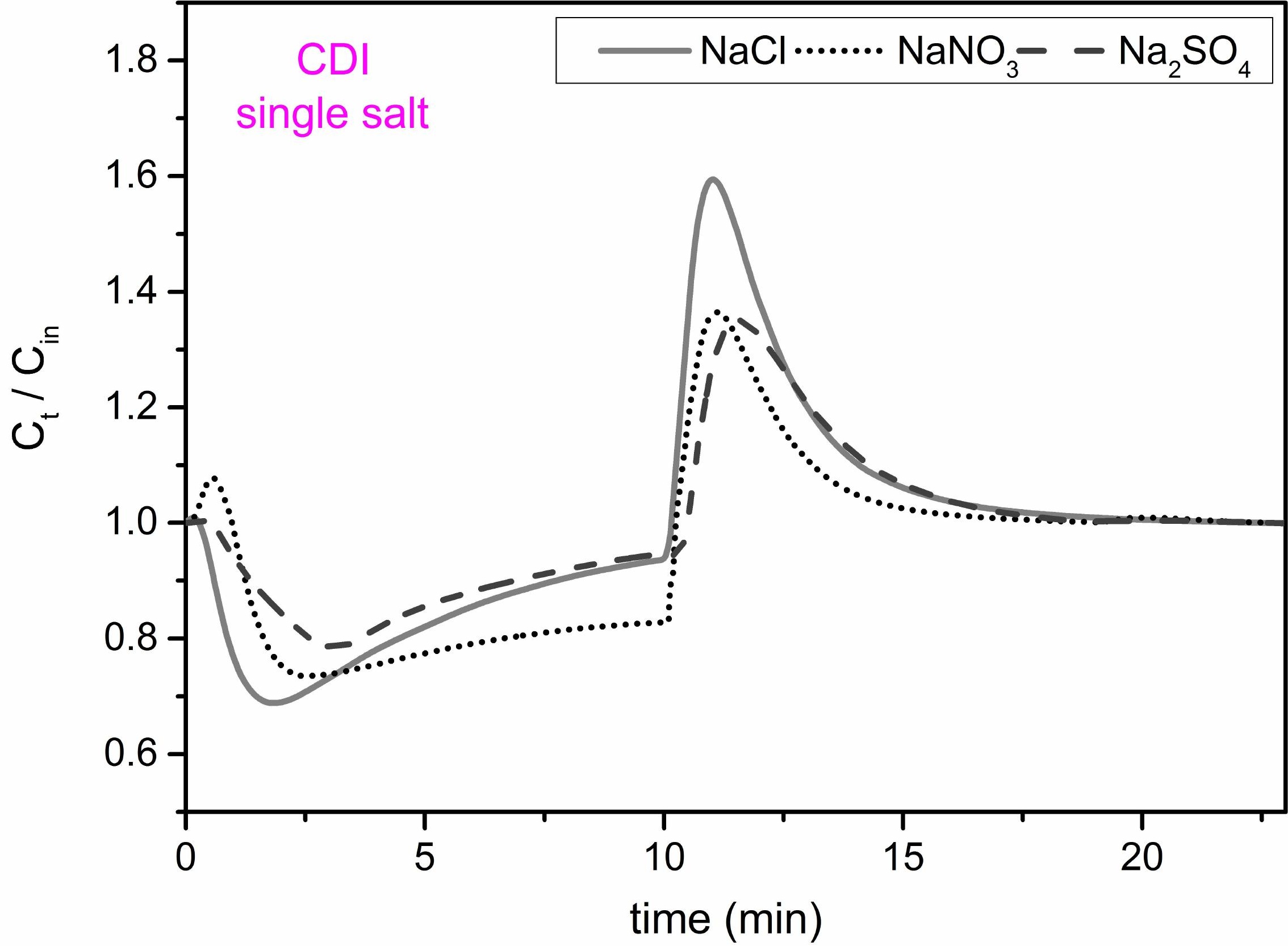




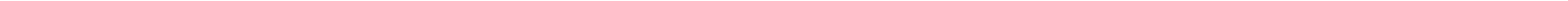




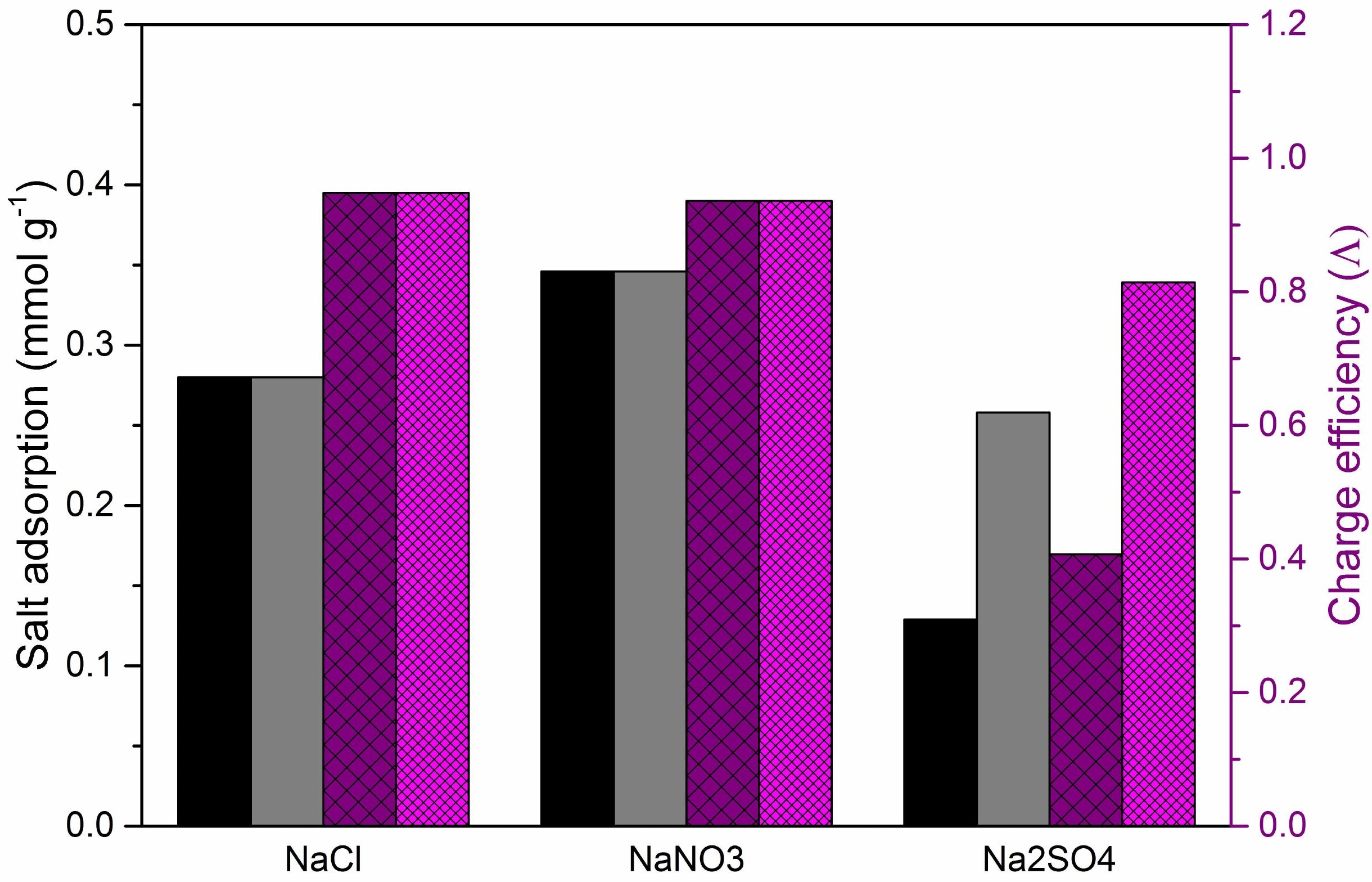




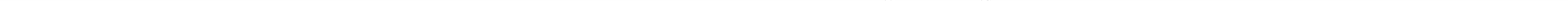




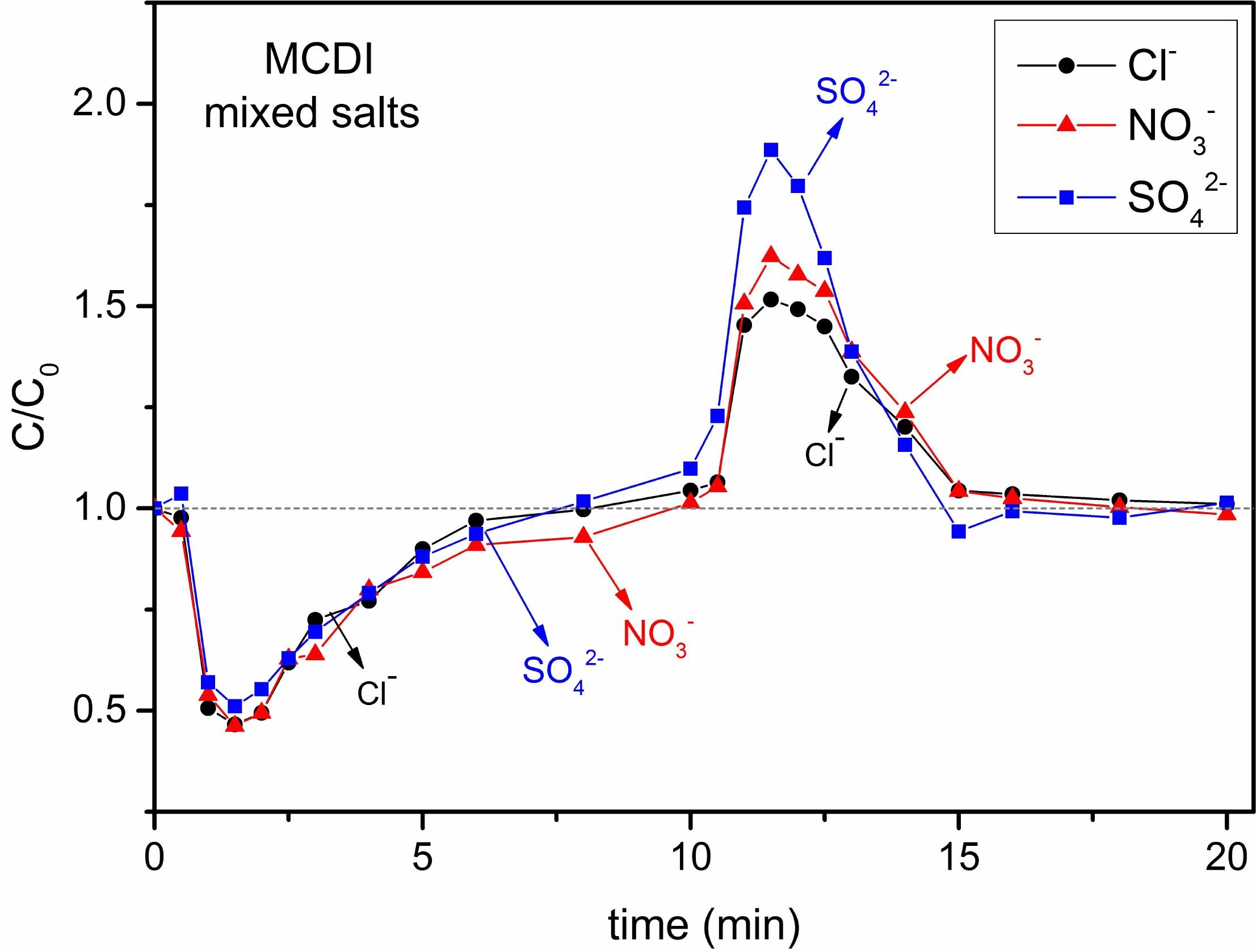




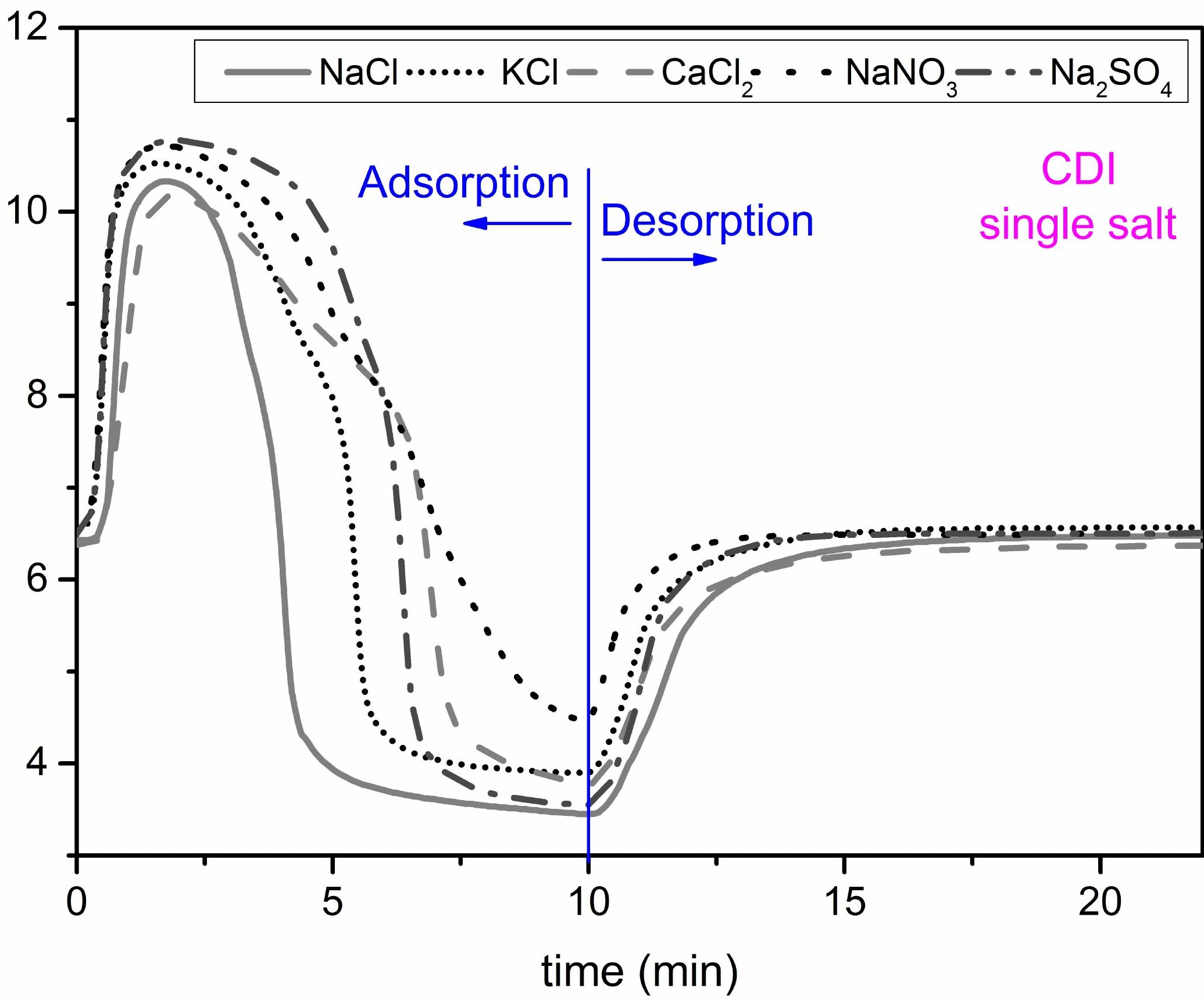




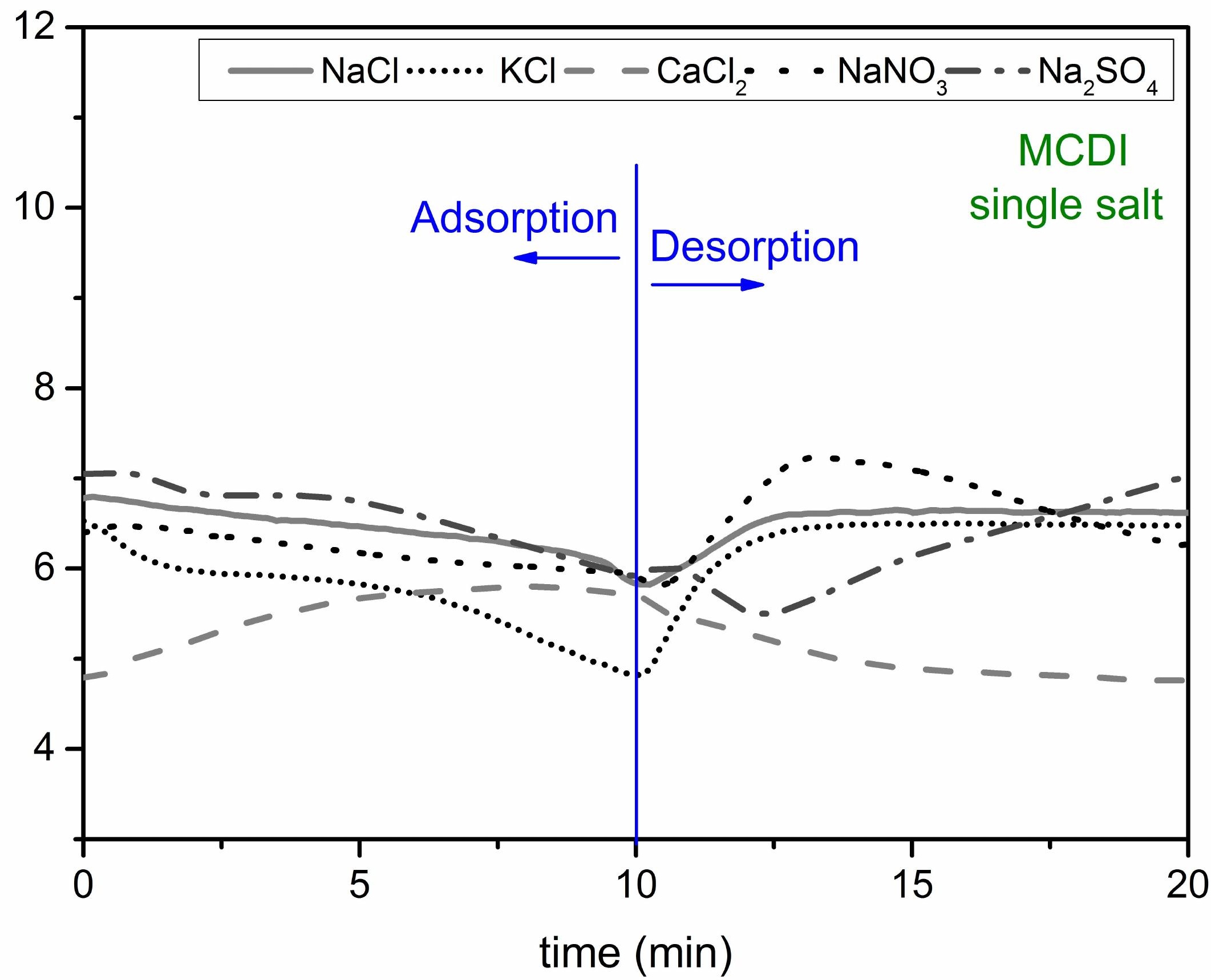

